\title{
Changes in urocanic acid, histamine, putrescine and cadaverine levels in Indian mackerel (Rastrelliger kanagurta) during storage at different temperatures
}

\begin{abstract}
Histamine, putrescine cadaverine and cis-urocanic acid (UCA) have all been implicated or suggested in scombroid fish poisoning. However, there is little information on UCA especially during storage. Changes in their contents during storage of whole Indian mackerel at $0,3 \pm 1,10 \pm 1$ for up to 15 days and $23 \pm 2{ }^{\circ} \mathrm{C}$ for up to 2 days were monitored. Fresh muscles contained $14.83 \mathrm{mg} / \mathrm{kg}$ trans-UCA, $2.23 \mathrm{mg} / \mathrm{kg}$ cis-UCA and $1.86 \mathrm{mg} / \mathrm{kg}$ cadaverine. Histamine and putrescine were not detected. After 15 days at 0 and $3{ }^{\circ} \mathrm{C}$, trans-UCA content increased to 52.83 and $189.51 \mathrm{mg} / \mathrm{kg}$, respectively, and decreased to $<2 \mathrm{mg} / \mathrm{kg}$ at the other two temperatures. Storage at $10{ }^{\circ} \mathrm{C}$ also resulted in an increase in trans-UCA after 3 days, only to decrease after 6 days. The concentration of cis-UCA increased nearly 13 -fold after 15 days at 0 and $3{ }^{\circ} \mathrm{C}$, decreased at $10{ }^{\circ} \mathrm{C}$ and remained unchanged at $23{ }^{\circ} \mathrm{C}$. Histamine, putrescine and cadaverine levels increased significantly $(\mathrm{P}$ value $<0.05)$ at all temperatures especially at $23{ }^{\circ} \mathrm{C}$.
\end{abstract}

Keyword: Urocanic acid; Biogenic amine; Histamine; Putrescine; Cadaverine; Indian mackerel; Storage 